\title{
Anterior cervical discectomy and fusion for the management of axial neck pain in the absence of radiculopathy or myelopathy
}

\author{
Authors: K Daniel Riew ${ }^{1}$, Erika Ecker², Joseph R Dettori ${ }^{2}$ \\ Institutions: ${ }^{1}$ Washington University Orthopaedics, Barnes-Jewish Hospital, St. Louis, MO, USA \\ ${ }^{2}$ Spectrum Research, Inc., Tacoma, WA, USA
}

\section{ABSTRACT}

Study design: Systematic review

Study rationale: Anterior cervical discectomy and fusion (ACDF) is a proven, effective treatment for relieving neck pain due to degenerative conditions of the cervical spine. Since most patients also present with radiculopathy or myelopathy, little is known as to the effectiveness of ACDF to relieve pain and improve function in patients without radicular or myelopathic symptoms.

Objective: To examine the clinical outcome in patients undergoing (ACDF) for axial neck pain without radicular or myelopathic symptoms.

Methods: A systematic review was undertaken for articles published up to March 2010. Electronic databases and reference lists of key articles were searched to identify studies evaluating ACDF for the treatment of axial neck pain only. Radiculopathy and myelopathy, patients who suffered severe trauma, or with tumor/metastatic disease or infection were excluded. Two independent reviewers assessed the strength of evidence using the grading of recommendations assessment, development and evaluation (GRADE) system, and disagreements were resolved by consensus.

Results: No comparative studies were identified. Three case series met our inclusion criteria and were evaluated. All studies showed a mean improvement of pain of at least $50 \%$ approximately 4 -years following surgery. Functional outcomes improved between $32 \%$ and $52 \%$ from baseline. Most patients reported satisfaction with surgery, 56\% in one study and $79 \%$ in another. Complications varied among studies ranging from $1 \%$ to $10 \%$ and included pseudoarthrosis (9\%), nonunion and revision (3\%) and screw removal (1\%).

Conclusion: There is low evidence suggesting that patients with axial neck pain without radicular or myelopathic symptoms may receive some improvement in pain and function following ACDF. However, whether this benefit is greater than nontreatment or other treatments cannot be determined with the present literature. 


\section{STUDY RATIONALE AND CONTEXT}

ACDF is a commonly performed procedure for degenerative conditions of the cervical spine with a successful fusion rate of approximately $95 \%$ and with overall good to excellent results $[1,3]$. The majority of patients present with combined complaints of axial neck pain with associated upper extremity radicular or myelopathic symptoms. There is considerable controversy, however, regarding the role of ACDF for neck pain without radiculopathy or myelopathy, and clinical outcome studies of ACDF with validated outcome measures in this patient population are scarce.

\section{OBJECTIVES}

To analyze the clinical outcome in patients treated with ACDF for axial neck pain in the absence of radiculopathy or myelopathy, especially with regard to changes in pain and function.

Fig 1 Flow chart showing results of literature search

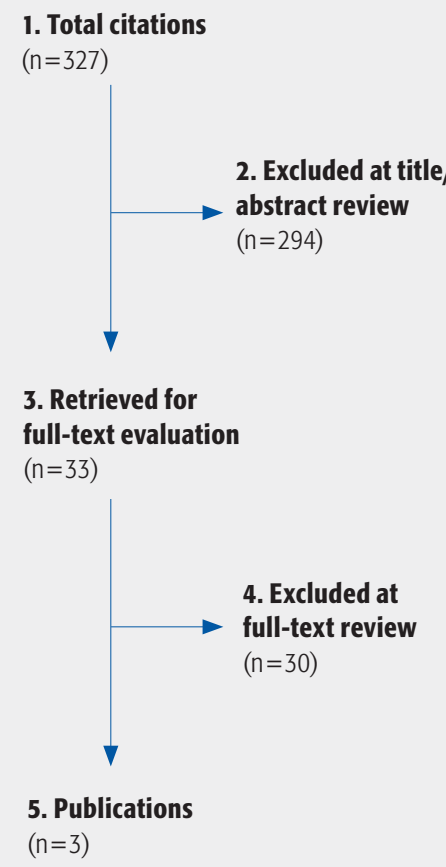

Volume 1/Issue 3-2010

\section{MATERIALS AND METHODS}

Study design: Systematic review

\section{Sampling:}

Search: PubMed, Cochrane collaboration database, and National Guideline Clearinghouse databases; bibliographies of key articles

Dates searched: through March 2010

Inclusion criteria: (1) axial neck pain only as primary indication for ACDF, (2) failed conservative treatment Exclusion criteria: (1) radiculopathy, (2) myelopathy, (3) arm pain, (4) severe trauma (fracture, fracture-dislocation), (5) tumor/metastatic disease, (6) infection

Outcomes: Pain-visual analog scale (VAS), numerical rating scale (NRS); patient-reported function (modified Oswestry disability index, Roland and Morris disability index), patient satisfaction modified North American Spine Society outcome questionnaire, patient satisfaction index; and complications

Analysis: Descriptive statistics

Table 1 Patient demographics for case series reporting ACDF for the treatment of axial neck pain without radiculopathy or myelopathy

\begin{tabular}{|c|c|c|c|c|}
\hline $\begin{array}{l}\text { Author } \\
\text { (year) }\end{array}$ & $\begin{array}{l}\text { Study type } \\
\text { (class of } \\
\text { evidence) }\end{array}$ & Demographics & $\begin{array}{l}\text { Levels } \\
\text { fused }\end{array}$ & Follow-up \\
\hline 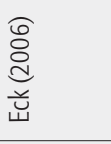 & 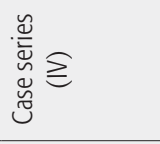 & $\begin{array}{l}\mathrm{N}=41 \\
\text { Male: } 46 \% \\
\text { Age: } 56(39-76)\end{array}$ & $\begin{array}{l}1, n=23(56 \%) \\
2, n=14(34 \%) \\
3, n=4(10 \%)\end{array}$ & $\begin{array}{l}3.5 \text { years } \\
(1.2-5.6)\end{array}$ \\
\hline 离灾 & 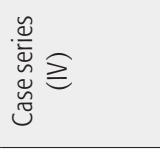 & $\begin{array}{l}\mathrm{N}=87 \\
\text { Male: } 38 \% \\
\text { Age: } 45(21-74)\end{array}$ & $\begin{array}{l}1, n=34(39 \%) \\
2, n=32(37 \%) \\
3, n=12(14 \%) \\
4, n=9(10 \%)\end{array}$ & $\begin{array}{l}4.4 \text { years } \\
( \pm 1.5)\end{array}$ \\
\hline 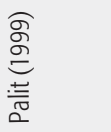 & 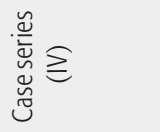 & $\begin{array}{l}\mathrm{N}=38 \\
\text { Male: } 42 \% \\
\text { Age: } 42(26-61)\end{array}$ & $\begin{array}{l}1, n=21(55 \%) \\
2, n=16(42 \%) \\
3, n=1(3 \%)\end{array}$ & $\begin{array}{l}4.4 \text { years } \\
(2-7.3)\end{array}$ \\
\hline
\end{tabular}

Table 2 Patient satisfaction and repeat surgery

\begin{tabular}{lll}
\hline Study & $\begin{array}{l}\text { Patient satisfied: extremely/ } \\
\text { very or somewhat }\end{array}$ & $\begin{array}{l}\text { Repeat } \\
\text { surgery: yes }\end{array}$ \\
\hline Eck $(\mathrm{N}=41)$ & $\mathrm{NR}$ & $88 \%$ \\
\hline Carvey $^{*}(\mathrm{~N}=87)$ & $56 \%$ & $87 \%$ \\
\hline Palit $^{\dagger}(\mathrm{N}=38)$ & $79 \%$ & $\mathrm{NR}$ \\
\hline
\end{tabular}

$N R=$ not reported

${ }^{*}$ North American Spine Society outcome questionnaire

tPatient satisfaction index 


\section{RESULTS}

We found no studies comparing ACDF with conservative treatment for axial neck pain without radiculopathy or myelopathy. However, three case series, all graded class of evidence IV, met our inclusion criteria and form the basis for this report (Fig $\mathbf{1}$ ). Further details on the class of evidence determination can be found in the web appendix at www.aospine.org/ebsj.

Characteristics of each study are outlined in Table 1. Overall, a total of 166 patients were included, with ages ranging from 21 to 76 years of age, and comprised of slightly more females than males. The majority of patients underwent 1 or 2-level fusion $(84 \%, \mathrm{n}=140)$ followed by 3 or 4 level fusion $(16 \%, n=26)$.

\section{Pain (Fig 2)}

- All studies reported a mean improvement of over $50 \%$ at approximately 4 -years follow-up, regardless of the number of levels fused.

\section{Patient reported functional outcomes (Fig 3)}

- Overall mean functional scores improved significantly compared with preoperative scores at approximately 4 years after surgery. Mean percent age improvement in ODI ranged from $32.3 \%$ to $51.9 \%$ across the three studies $[2,4,5]$. For the RMDI, a mean improvement of over $50 \%$ was seen in all patients, including sub-group analyses of 1 to 2-level and $\geq 3$-level fusion, in one study [4].

\section{Patient satisfaction and repeat surgery (Table 2)}

- In two studies, $56 \%(\mathrm{n}=49)$ and $79 \%(\mathrm{n}=30)$ of patients reported that they were satisfied with the surgical outcome $[4,5]$.

- Over $85 \%$ of patients in two studies said they would repeat the surgery $[2,4]$.

\section{Complications}

- In one study, pseudoarthrosis occurred in eight $(9.2 \%)$ patients and reoperation for screw removal in one (1\%) [4].

- In another study, nonunion occurred in one $(3 \%)$ patient requiring revision [5].

Fig 2 Overall mean percent age improvement in pain scores at last follow-up across the three case series

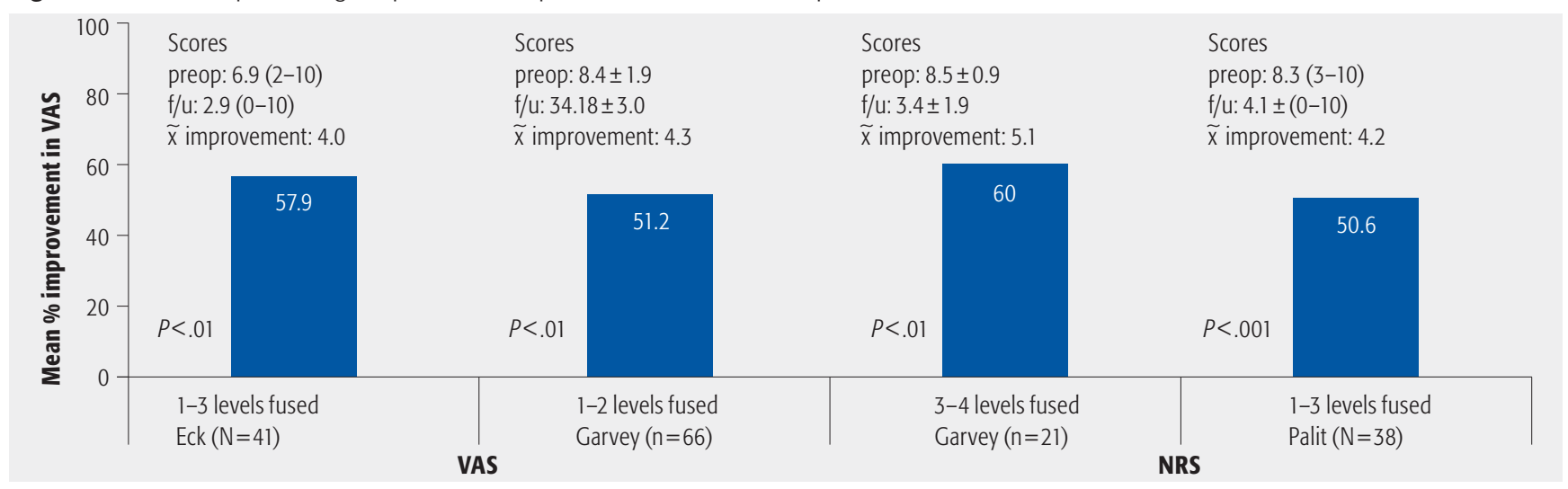

NRS = numerical rating scale; $V A S=$ visual analog scale; $f / u=$ follow-up; preop = preoperative

Fig 3 Overall mean percent age improvement in Owestry disability index and Roland and Morris disability index function scores at last follow-up across the three case series

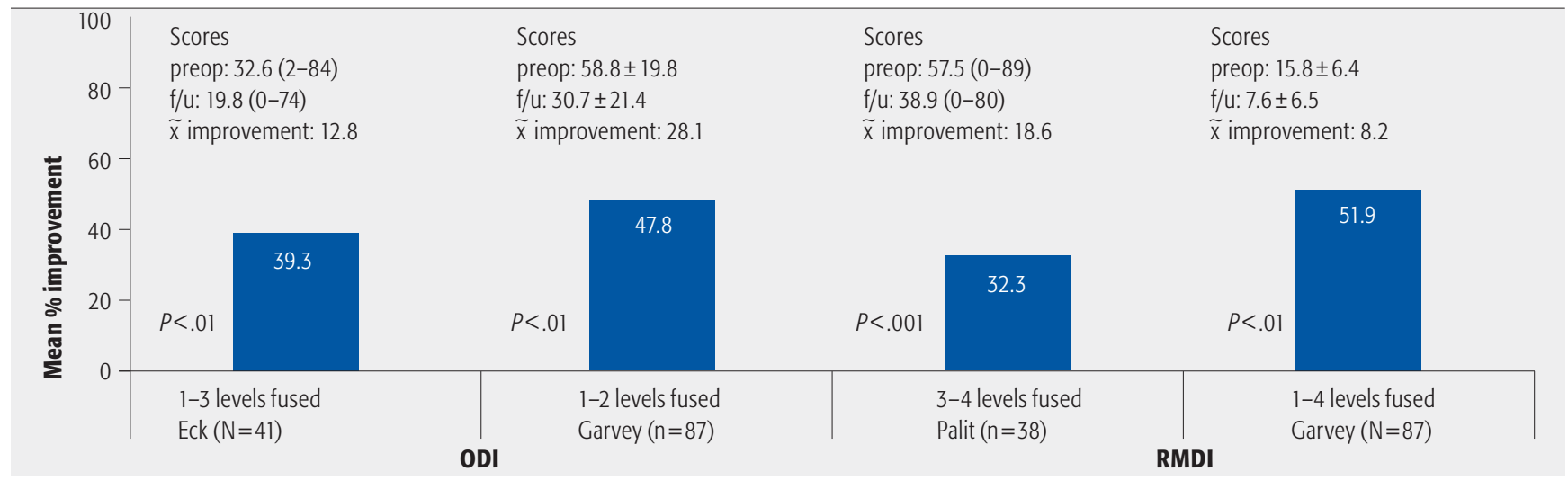

$\mathrm{ODI}=$ Oswestry disability index; $\mathrm{RMDI}=$ Roland \& Morris disability index; $\mathrm{f} / \mathrm{u}=$ follow-up; preop = preoperative 


\section{CLINICAL GUIDELINES}

No clinical guidelines were found addressing this question.

\section{EVIDENCE SUMMARY}

Anterior cervical discectomy and fusion (ACDF) for the management of neck pain in the absence of radiculopathy or myelopathy

\begin{tabular}{|c|c|c|}
\hline Outcomes & Strength of evidence & Conclusions/comments \\
\hline Pain & Low & $\begin{array}{l}\text { Three small case series suggest } \\
\text { that ACDF may result in } \\
\text { improvement in pain (>50\% } \\
\text { mean improvement compared } \\
\text { with baseline) for patients with } \\
\text { axial neck pain only. }\end{array}$ \\
\hline Function & Low & $\begin{array}{l}\text { The same three case series } \\
\text { suggest that an improvement in } \\
\text { ODI scores (32\%-48\% } \\
\text { improvement at last follow-up } \\
\text { compared with baseline) may } \\
\text { be achieved following ACDF in } \\
\text { this patient population. } \\
\text { A similar significant } \\
\text { improvement in RMDI scores } \\
\text { was achieved in one study. } \\
\text { Whether the benefit in pain and } \\
\text { function is greater than non } \\
\text { treatment or other treatments } \\
\text { cannot be determined with the } \\
\text { present literature. }\end{array}$ \\
\hline $\begin{array}{l}\text { Patient } \\
\text { satisfaction/ } \\
\text { repeat surgery }\end{array}$ & Low & $\begin{array}{l}\text { The majority of patients who } \\
\text { receive ACDF for the treatment } \\
\text { of axial neck pain only report } \\
\text { that they are satisfied with the } \\
\text { surgical outcome ( } 56 \%-79 \%) \\
\text { and would repeat the surgery if } \\
\text { necessary (87\%). }\end{array}$ \\
\hline
\end{tabular}

\section{ILLUSTRATIVE CASE}

A 43-year-old physically fit woman, with a history of tobacco abuse presented with a prolonged history of axial neck pain, recalcitrant to nonoperative treatments (Fig 4). Preoperative lateral x-rays showing degenerative disc disease at C4-7, with mild kyphosis (Fig 5). We strongly discouraged surgical treatment and recommended aerobic exercise. She returned several years later, having undergone a C4-7 ACDF with allograft elsewhere. The surgery helped for only a few months. X-rays, CT, and MRI revealed degenerative changes and mild anterolisthesis at C7-T1 and pseudoarthroses at C4-5 and C6-7 (Figs 6-8). Pseudoarthrosis repair was performed, noting that C7-T1 might require future surgery. Revision ACDF resulted in approximately $75 \%$ resolution of her axial pain (Fig 9).

Fig 4 Preoperative lateral $x$-ray showing degenerative disc disease at C4-7, with mild kyphosis

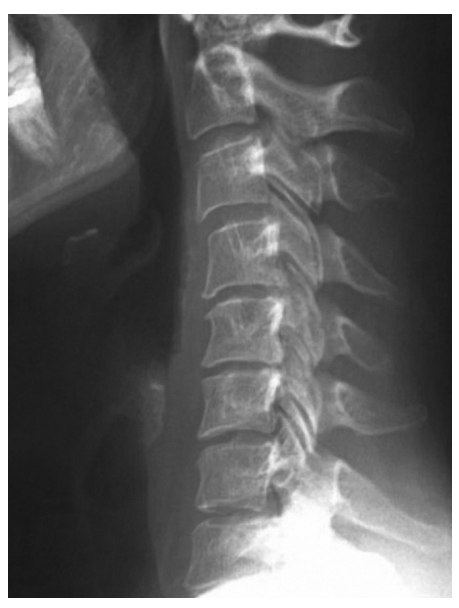

Fig 5 Preoperative mid-sagittal MRI showing degenerative disc disease at C4-7

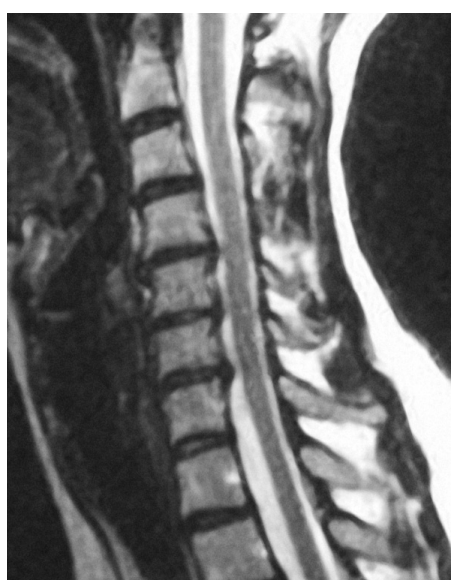




\section{DISCUSSION}

- Limitations of our SR:

1. Small number of studies available to address the issue, all with small sample sizes $(n=38, n=41, n=87)$.

2. No comparative studies available to compare outcomes with nonsurgical treatment.

3. All studies are case series, class of evidence IV.

4. The proportion of patients who achieve a clinically meaningful improvement in pain and function $\geq 30 \%$ is not reported.

5. There is no reference made to restoration of physiologic sagittal cervical spine with fusion patients.

6. Selection of fusion levels and integrity of discs adjacent to the operated levels is insufficiently addressed.

7. The role of provocative testing (ie, injections, blocks, cervical discography) was not addressed in this review and was not systematically used in the case series analyzed in this systematic review.

Fig 6 Lateral $x$-ray revealing degenerative changes and mild anterolis thesis at C7-T1 and pseudoarthroses at C4-5 and C6-7 after index ACDF

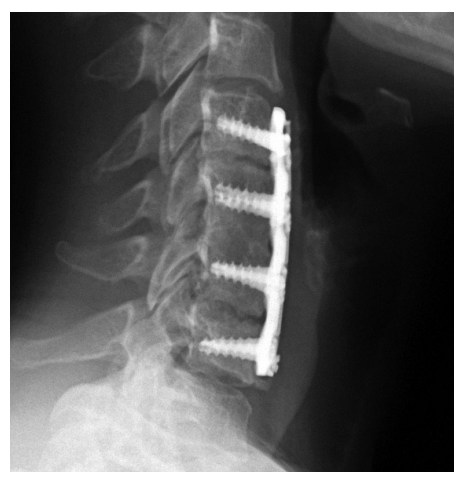

Fig 8a Coronal reconstruction of $\mathrm{CT}$ revealing degenerative changes and mild antero-listhesis at $\mathrm{C} 7-\mathrm{T} 1$ and pseudoarthroses at C4-5 and C6-7 after index ACDF

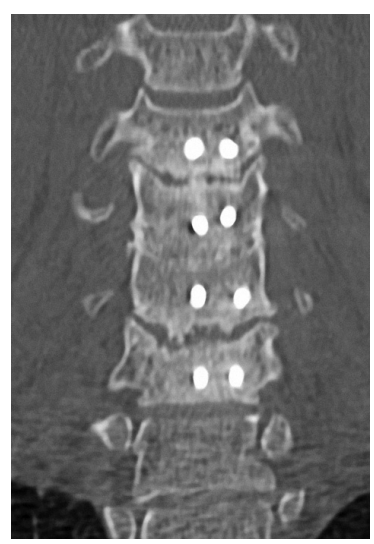

Fig 8b Sagittal reconstruction of $\mathrm{CT}$ revealing degenerative changes and mild anterolisthesis at $\mathrm{C} 7-\mathrm{T} 1$ and pseudoarthroses at C4-5 and C6-7 after index ACDF

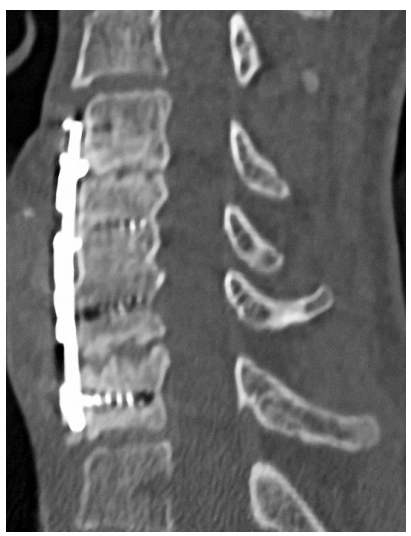

- There is no class of evidence I-III data regarding the success rate of surgical treatment for axial neck pain. The lack of data may reflect the reluctance of academic spine surgeons to operate on axial neck pain in the absence of neurological symptoms.

- Surgery for the treatment of axial neck pain remains controversial and there is scant literature to guide treatment of any form-operative and nonoperative.

- In two studies, $56 \%(\mathrm{n}=49)$ and $79 \%(\mathrm{n}=30)$ of patients reported that they were satisfied with the surgical outcome.

- A prospective randomized controlled study comparing surgical treatment to nonoperative measures, including aerobic exercise is needed, and due to the demonstrated relative therapeutic equipoise, appears ethically warranted.

Fig 7 MRI revealing degenerative changes and mild anterolisthesis at C7-T1 and pseudoarthroses at C4-5 and C6-7 after index ACDF

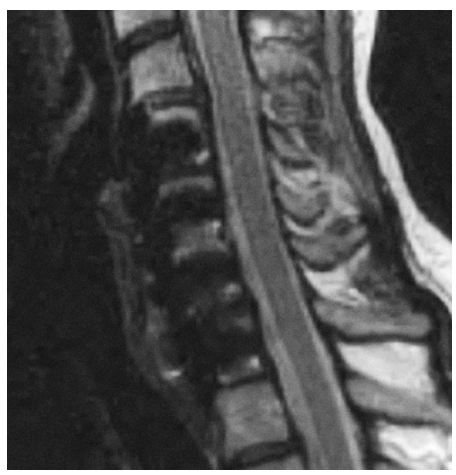

Fig 9 Six weeks postoperative lateral $x$-ray following revision ACDF

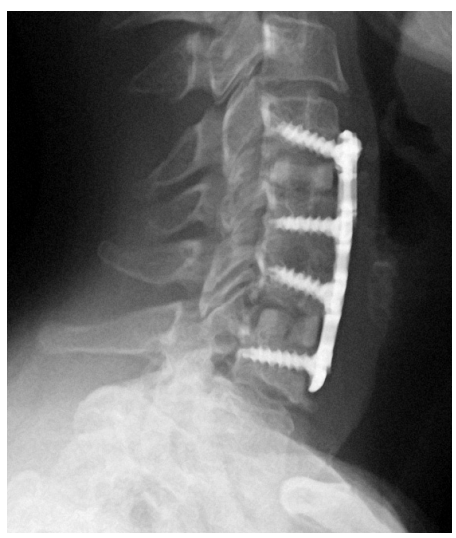




\section{REFERENCES}

1. Brodke DS, Zdeblick TA (1993) Modified Smith-Robinson procedure for anterior cervical fusion for spondylotic myeloradiculopathy. Spine; 19:2167-2173.

2. Eck JC, Humphreys SC, Hodges SD, et al (2006) A comparison of outcomes of anterior cervical discectomy and fusion in patients with and without radicular symptoms. J Surg Orthop Adv; 15(1):24-26.

3. Emery SE, Bolesta MJ, Banks MA, et al (1994) Robinson anterior cervical fusion: comparison of the standard and modified techniques. Spine; 19(6):660-663.

4. Garvey TA, Transfeldt EE, Malcolm JR, et al (2002) Outcome of anterior cervical discectomy and fusion as perceived by patients treated for dominant axial-mechanical cervical spine pain. Spine; 27(17):1887-1895; discussion 1895.

5. Palit M, Schofferman J, Goldthwaite $\mathbf{N}$, et al (1999) Anterior discectomy and fusion for the management of neck pain. Spine; 24(21):2224-2228.

\section{EDITORIAL STAFF PERSPECTIVE}

The subject of treatment for neck pain with anterior cervical discectomy and fusion and the methodology and findings of our authors evoked considerable debate among our reviewers. The inclusion of only three articles with a limited overall cohort was mentioned as a considerable limitation to the ability to conduct meaningful data analysis. Of course the vast mainstay of the available scientific literature reflects the overwhelming clinical indication for an anterior cervical discectomy and fusion in the setting of a degenerative disc disease. As is apparent in this formal systematic review, few authors have ventured beyond the accepted gold standards for ACDF to date. The second biggest controversy revolved around a subject, which will become increasingly contentious in the future, of the degree of improvement as measured in clinically related health outcomes questionnaires. In the three studies that met the inclusion criteria of the authors, the objective percentage of improvement in neck pain was between $50 \%$ and $60 \%$ at 4 years; the patient satisfaction was $56 \%$ and $79 \%$ in the two studies from which the data can be abstracted, and functional outcomes improved between $32 \%$ and $52 \%$ from baseline. Are these differences meaningful enough to warrant performing these procedures? The questions of level selection, restoration of normal sagittal alignment and actually achieving a solid fusion were felt to be considerable variables potentially affecting patient outcomes. Furthermore, how long do these results last? And the as yet unanswered question: does the presence of a rigidly fused level in the lower C-spine set an affected patient up for a cascade effect on other levels later on?

Certainly ACDF seems to have a positive treatment effect on patients who have failed nonoperative care for symptomatic cervical disc disease. The presented results do provide a justification of more formal study of this subject area. 